[2] Ponchel, et al. Ann Rheum Dis 2014;73:2047-53.

[3] Saevarsdottir, et al. Ann Rheum Dis 2011;70:469-75.

[4] Wessels, et al. Arthritis Rheum 2006;54:2830-9.

[5] Saevarsdottir, et al. Arthritis Rheum 2011;63:26-36.

[6] Tan, et al. Int J Rheum Dis 2016;19:482-9.

[7] Bugatti, et al. Ann Rheum Dis 2017;76:790-1.

[8] Stühlmuller, et al. Clin Immunol 2016;171:50-61.

[9] Carini, et al. J Transl Med 2018;16:1-11.

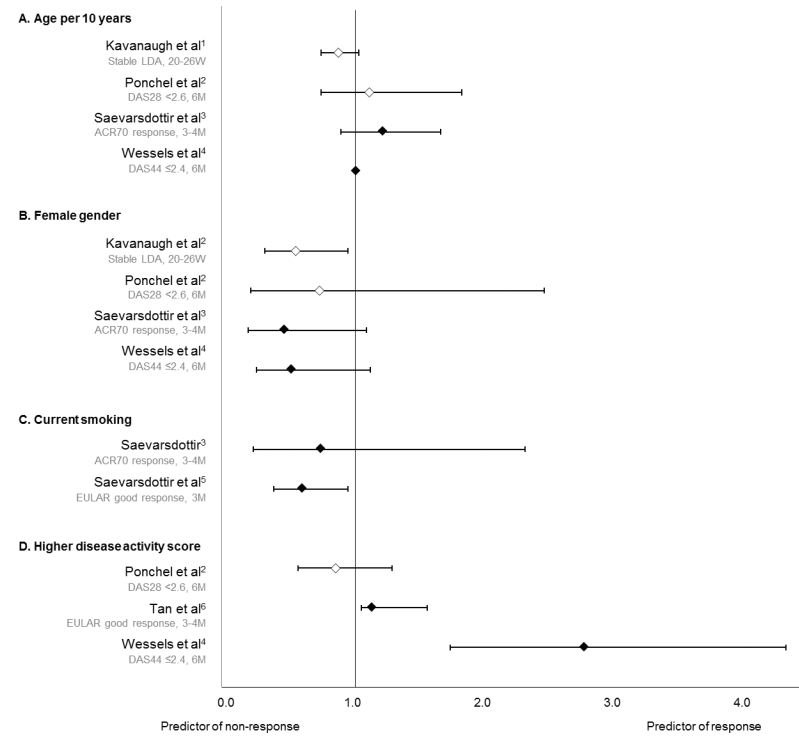

Figure 1. Associations between baseline predictors and response to MTX according to different outcome criteria and at different time points, in odds ratios with $95 \%$ confidence interval.

Odds ratios are shown as diamonds: White diamonds represent univariate analyses; black diamonds multivariate analyses; and whiskers $95 \%$ confidence intervals. Used response criteria and time points of clinical response are shown in grey type for each study. DAS28: disease activity score assessing 28 joints; DAS44: disease activity score assessing 44 joints; LDA: low disease activity (definition not specified in article); M: months; W: weeks.

Disclosure of Interests: Nadia M. T. Roodenrijs: None declared, Marlies van der Goes: None declared, Paco Welsing: None declared, Janneke Tekstra: None declared, Jacob M. van Laar Grant/research support from: Genentech, Consultant for: F. Hoffmann-La Roche, Floris Lafeber Shareholder of: ArthroSave, Grant/research support from: FOREUM; Dutch Arthritis Society, Johannes WJ Bijlsma Grant/research support from: The department of the author who included patients (JWJB) in the U-Act-Early trial received reimbursements from Roche Nederland BV. JWJB reported grants and fees from Roche, AbbVie, Bristol-Myers Squibb, Merck Sharp \& Dohme, Pfizer, and UCB

University Medical Center Utrecht, Utrecht University, Consultant for: SUN Pharma, Speakers bureau: Lilly, Roche, Johannes W. G. Jacobs Grant/ research support from: Roche, Consultant for: Roche

DOI: 10.1136/annrheumdis-2019-eular.4176

\section{AB0277 EFFECT OF DISEASE DURATION AND OTHER PATIENT BASELINE CHARACTERISTICS ON OUTCOMES IN TOCILIZUMAB-TREATED RHEUMATOID ARTHRITIS PATIENTS: A POOLED ANALYSIS}

Andrea Rubbert-Roth ${ }^{1}$, Daniel Aletaha ${ }^{2}$, Jenny Devenport ${ }^{3}$, Paris N. Sidiropoulos ${ }^{3}$, Yves Luder ${ }^{4}$, Michael Edwardes ${ }^{5}$, Johannes W. G. Jacobs ${ }^{6} .{ }^{1}$ Kantonsspital $S t$ Gallen, St Gallen, Switzerland; ${ }^{2}$ Medical University of Vienna, Vienna, Austria; ${ }^{3}$ Genentech, South San Francisco, United States of America; ${ }^{4} \mathrm{~F}$ Hoffmann-La Roche, Basel, Switzerland; ${ }^{5}$ Everest Clinical Research, Markham, Canada; ${ }^{6}$ University Medical Center, Utrecht, Netherlands

Background: Tocilizumab (TCZ) efficacy and safety in rheumatoid arthritis (RA) have been well established by numerous phase 3 and 4 studies and observational studies.

Objectives: To explore the extent to which disease duration, inflammation, disease burden, and other baseline factors explain variations in outcomes in studies of RA patients treated with TCZ.

Methods: This was a pooled analysis of methotrexate-inadequate responding (IR)/conventional synthetic disease-modifying antirheumatic drug (csDMARD)-IR patients with RA allocated to TCZ (intravenous or subcutaneous, monotherapy + combination therapy) in phase 3 and 4 studies. End points were change from baseline to week 24 in Clinical Disease Activity Index (CDAI) and quality of life (Health Assessment Questionnaire-Disability Index [HAQ-DI]) and week 24 ACR50 and CDA remission ( $\leq 2.8)$. Using a combination of clinically informed and mathematically driven variable selection techniques, models (with study included as a random effect to account for intracorrelation of observations within each study) were built to optimize fit and explain outcome variance. Analysis of covariance and logistic regression were used for CDAl/HAQ-DI change from baseline and for ACR50/CDAI remission, respectively.

Results: The analyses were performed on 5462 patients from 12 studies. Analysis of baseline characteristics (before TCZ administration) revealed that patients with longer disease duration had been exposed to more CSDMARDS and had worse HAQ-DI than patients with shorter disease duration. Statistical modeling of clinical outcomes showed that disease duration accounted for $<2 \%$ of the variation in HAQ-DI and CDAl change from baseline. Baseline CDAl explained $32 \%$ of the variation in CDAl change from baseline. Patients with higher baseline CDAI values tended to have greater improvements, likely due to having more "room" for improvement and to a higher risk for regression to the mean resulting from the fact that inclusion criteria for most trials required defined thresholds of disease activity, including joint counts. Baseline HAQ-DI, neither an inclusion criterion itself nor influenced by other inclusion criteria, explained $15 \%$ of the variation in HAQ$\mathrm{DI}$ change from baseline. The odds of achieving ACR50 decreased by $9.2 \%$ if disease duration was doubled. The odds of achieving CDAl remission decreased by $15 \%$ per 5 additional years of disease duration and decreased by $22 \%$ per 10 additional score units of CDAl at baseline.

Conclusion: In this pooled analysis of TCZ-treated RA patients, disease duration explained statistically significant but practically small variations in clinical outcomes. These findings indicate that TCZ treatment outcomes are not heavily influenced by disease duration or other baseline characteristics. Disclosure of Interests: Andrea Rubbert-Roth Consultant for: Chugai, El Lilly, Roche, and Sanofi, Speakers bureau: AbbVie, Bristol-Myers Squibb, Chugai, Hexal/Novartis, Janssen, Eli Lilly, Merck Sharp \& Dohme, Pfizer, Roche, and Sanofi, Daniel Aletaha Grant/research support from: AbbVie, Bristol-Myers Squibb, and MSD, Consultant for: AbbVie, Bristol-Myers Squibb, El Lilly, Janssen, Medac, Merck, MSD, Pfizer Inc, Roche, and UCB, Speakers bureau: AbbVie, Bristol-Myers Squibb, Eli Lilly, Janssen, Medac, Merck, MSD, Pfizer Inc, Roche, and UCB, Jenny Devenport Employee of: F. Hoffmann-La Roche, Paris N. Sidiropoulos Shareholder of: Roche, Employee of: Genentech, Yves Luder Shareholder of: F. Hoffmann-La Roche, Employee of: F. Hoffmann-La Roche, Michael Edwardes Consultant for: Roche, Johannes W. G. Jacobs Grant/research support from: Roche, Consultant for: Roche DOI: 10.1136/annrheumdis-2019-eular.1144

\section{AB0278 DISCRIMINANT VALIDITY OF THE HANDGRIP STRENGTH TEST IN PATIENTS WITH RHEUMATOID ARTHRITIS: A COHORT STUDY}

Fausto Salaffi ${ }^{1}$, Sonia Farah ${ }^{1}$, Marco DI Carlo ${ }^{1}$, Giacomo Beci ${ }^{1}$, Marina Carotti ${ }^{2}$. ${ }^{1}$ Hospital "Carlo Urbani", Dipartimento scienze cliniche e molecolari, Jesi, Italy; ${ }^{2}$ Ospedali Riuniti Torrette Di Ancona, Dipartimento Radiologia, Torrette, Ancona, Italy

Background: Hand involvement is one of the major determinants of disease outcome affecting the ability to perform activities of daily living and other functional activities in rheumatoid arthritis (RA). Handgrip strength (HS) provides a clinically validated marker of functional disability.

Objectives: The aim of this study was to assess discriminant validity of $\mathrm{HS}$ and to compare it with the Quick Disabilities of Arm Shoulder and Hand (Quick-DASH) (1), Arthritis Impact Measurement Scales 2 (AIMS-2), Hand Health Assessment Questionnaire (Hand HAQ) and Recent-Onset Arthritis Disability (ROAD) upper extremity index (2).

Methods: In this transversal study, a total of 291 patients with RA responding to the ACR 2010 criteria were evaluated. HS was measured twice for both hands by the use of an electronic grip device. The instrument consists of a cylindrical-shape grip device made of 5 force sensors connected to a microcontroller. The correlations between indices were studied through the Pearson's correlation coefficient $(r)$. The discriminatory ability of HS [cut-off values, male $\leq 27 \mathrm{Kg}$, female $\leq 16 \mathrm{Kg}$ ], QuickDASH [range 0-100], AIMS-2 hand/finger function [range 0-10], Hand HAQ [range 0-21], and ROAD upper extremity function [range 0-10] were assessed using receiver operating characteristic (ROC) curves analysis. The external anchor was the general question on Patient Acceptable Symptom State (PASS) (3).

Results: The 239 female and 52 male patients (sex ratio: 4.5F/1M) were of a mean age of $56.5 \pm 12.3$ years $(20-81)$ and a disease duration of 
8.5 \pm 3.3 years (2 months-22 years). The HS mean $(\mathrm{Kg})$ was $20.9 \pm 7.1$ $[95 \% \mathrm{Cl} 20.07-21.7]$. The Quick-DASH mean was $28.08 \pm 11.90[95 \% \mathrm{Cl}$ 26.7-29.45]. The AIMS-2 hand and finger mean score was 4.5 \pm 2.21 [95\% Cl 4.24-4.75]. The Hand $\mathrm{HAQ}$ mean score was $9.8 \pm 4.3[95 \% \mathrm{Cl} 9.3$ 10.31] and the ROAD-upper extremity mean score was $4.75 \pm 2.11[95 \% \mathrm{Cl}$ 4.5-5]. A positive statistically significant correlation was noted between the five indices $(p<0.0001)$. The area under the ROC (AUC-ROC) were similar in all the measures although the HS showed the greatest discriminative ability (Table I and Figure 1)

Table 1. ROC curve analysis for the discriminatory power of functional disability, according to the different measures

\begin{tabular}{lccc}
\hline Variable & AUC & SE $^{\mathbf{a}}$ & $\mathbf{9 5 \%} \mathbf{~ C l ~}^{\text {b }}$ \\
\hline AIMS-2 hand/finger function & 0,839 & 0,0317 & 0,792 to \\
& & & 0,879 \\
Hand HAQ & 0,846 & 0,0306 & 0,799 to \\
& & 0,885 \\
QuickDASH & 0,863 & 0,0239 & 0,818 to \\
& & 0,900 \\
ROAD upper extremity & 0,816 & 0,0279 & 0,766 to \\
function & & & 0,858 \\
Handgrip strength (Kg) & 0,900 & 0,0206 & 0,860 to \\
& & & 0,932 \\
\hline
\end{tabular}

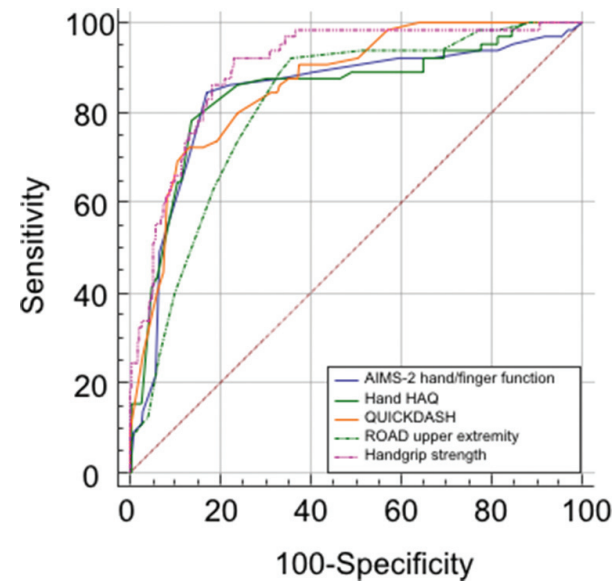

Figure 1. ROC of measures of upper extremity disease activity measures used in rheumatoid arthritis. ROC illustrating the relationship between sensitivity and complement of specificity (100-specificity) in RA for functional measures using PASS as an external indicator.

Conclusion: HS is a good alternative to the self-assessment functional indices for the evaluation of functional disability in RA. The use of an electronic grip device for HS measurement makes it easier to collect data and should be applied in both clinical trials and routine clinical care settings.

\section{REFERENCES}

[1] Salaffi F, Di Carlo M, Carotti M, Farah S. "Validity and interpretability of the QuickDASH in the assessment of hand disability in rheumatoid arthritis". Rheumatol Int. 2018 Dec 3.

[2] Salaffi F, Carotti M, Gutierrez M, Di Carlo M, De Angelis R. "Patient Acceptable Symptom State in Self-Report Questionnaires and Composite Clinical Disease Index for Assessing Rheumatoid Arthritis Activity: Identification of Cut-Off Points for Routine Care". Biomed Res Int. 2015

[3] Salaffi F, Stancati A, Neri R, Grassi W, Bombardieri S. "Measuring functional disability in early rheumatoid arthritis: the validity, reliability and responsiveness of the Recent-Onset Arthritis Disability (ROAD) index". Clin Exp Rheumatol. 2005 Sep-Oct;23(5 Suppl 39):S31-42.

Disclosure of Interests: Fausto Salaffi Grant/research support from: Abbvie, Roche, Novartis, BMS, Pfizer, Sanofi, Speakers bureau: Abbvie, Roche, Novartis, Pfizer, Sanofi, BMS, sonia farah: None declared, Marco Di Carlo: None declared, giacomo beci: None declared, marina carotti Speakers bureau: abbvie pfizer novartis roche bms sanofi DOI: 10.1136/annrheumdis-2019-eular.4598

\section{$\mathrm{AB} 0279$}

RENAL INVOLVEMANT AND CAUSES OF DEATH IN RHEUMATOID ARTHRITIS PATIENTS ACCORDING TO THE AUTOPSY DATA

Anastasia Tushina $^{1}$, Natalia Dostanko ${ }^{1}$, Viktor Yagur ${ }^{1}$, Nikolaj Soroka ${ }^{1}$,

Viktoria Dostanko ${ }^{2}{ }^{1}{ }^{B}$ Belarusian State Medical University, 2-nd Department of Internal Medicine, Minsk, Belarus; ${ }^{2}$ PMUE Infomed, Minsk, Belarus

Background: Renal involvement is a clinically significant manifestation in rheumatoid arthritis (RA) patients with potential influence on the treatment, prognosis and outcome of this disease while rare publications are available on kidney damage in RA $[1,2]$.

Objectives: To estimate the frequency and characteristics of renal involve ment and causes of death in RA patients on the basis of autopsy data reports and postmortem microscopic examinations.

Methods: We have analyzed 21814 autopsy data reports performed during 10-year period (2001-2010) and 6720 cases of autopsy performed 5 years later (2016-2018) in the Minsk City Clinical Pathologoanatomic Bureau (The Republic of Belarus).

Results: For the period 2001-2010 autopsies were performed in 110 RA patients: 91 women and 19 men of 67.0 (13.1) years old, M (SD). Renal involvement was revealed in 75 patients (68.2\%). The most common type of renal involvement was secondary AA amyloidosis - 44 patients (40\%). Other types of revealed renal lesions ( $n=31,28.2 \%)$ were mesangial proliferative glomerulonephritis $(n=3 ; 2.7 \%)$, nephroangiosclerosis $(n=14,12.8 \%)$, tubulointerstitial nephritis $(n=2,1.8 \%)$, chronic pyelonephritis $(n=10,9.1 \%)$ and renal vessel vasculitis $(n=2,1.8 \%)$.

The main cause of death in RA patients with amyloidosis was end-stage renal disease (ESRD, 43.2\%), whereas in other patients the common causes of death were cardiovascular events $(43.2 \%)$ and secondary infections $(33.3 \%)$. In case of secondary amyloidosis the deposits of amyloid were found in kidney of all RA patients (100\%), in adrenal glands - in $36.4 \%$ and in spleen - in $34.1 \%$ of RA patients. Amyloid deposits in other internal organs were not nearly as common.

In 2016-2018 50 patients with RA have been autopsied with mean age of death 72.0 (15.2) years old. Renal involvement was revealed in 34 $(68.0 \%)$ of autopsies: as secondary amyloidosis in 29 patients $(58.0 \%)$ and as focal segmental glomerulosclerosis or mesangial proliferative glomerulonephritis in 5 patients $(10.0 \%)$. The most common cause of death in this group of RA patients were cardiovascular events $(58.0 \%)$, fatal infectious complications developed in $16.0 \%$ of patients, ESRD was revealed only in $4.0 \%$ of patients.

Conclusion: 1. We have revealed an increase in secondary amyloidosis frequency in RA patients over the studied period of time from $40 \%$ to $58 \%(\mathrm{p}=0.041$. Fisher's exact test) while ESRD as a cause of death in RA patients decreased from $17.3 \%$ to $4 \%$ ( $p=0.023$, Fisher's exact test). 2. Secondary amyloidosis is the most common type of renal involvement in RA according to the autopsy data.

\section{REFERENCES}

[1] Makino H. et al. // Mod. Rheumatol. 2002;12(2):148-54

[2] Icardi A. et al. // Reumatismo. 2003;55(2):76-85.

Disclosure of Interests: None declared DOI: 10.1136/annrheumdis-2019-eular.4963

\section{AB0280 DIFFERENCE BETWEEN PATIENT'S GLOBAL HEALTH AND PATIENT'S GLOBAL ASSESSMENT OF DISEASE ACTIVITY, AND DIFFERENT FACTORS INFLUENCE ON THESE SCALES IN RHEUMATOID ARTHRITIS PATIENTS}

Naohiro Sugitani ${ }^{1,2}$, Yuki Mizutani $^{1}$, Kentaro Noda $^{1}$, Yasuo Suzuki $^{1}$,

Ayako Nakajima ${ }^{1} .{ }^{1}$ Mie University Hospital, Center for Rheumatic diseases, Tsu city, Mie, Japan; ${ }^{2}$ Tokyo Women's Medical University, Department of Rheumatology, Tokyo, Japan

Background: Evaluation of rheumatoid arthritis (RA) activity is crucia measurement in achieving remission or low disease activity. Visual ana logue scale (VAS) by patient's evaluation has been used for the outcome measure for RA patients because of its feasibility, reliability, sensitivity to change, and it directly reflects the patient's overall perspective. Patient's evaluation is a component of multiple composite indices used in assess ing RA activity and treatment response. There are two measurements that patient's evaluation. One is patient's global assessment of disease activity (PtGA), and the other is patient's assessment of global health $(\mathrm{PtGH})^{1)}$. PtGA was originally developed as a component of American College of Rheumatology Core Set and used for Simplified Disease Activ ity Index (SDAI) and Clinical Disease Activity Index (CDAI); while PtGH was originally developed as a component of 28-joint Disease Activity Score (DAS28). PtGA and PtGH have been considered equivalent in a 